\title{
Benchmarking and improving dimensional quality on modular construction projects - A case study
}

\author{
Christopher RAUSCH${ }^{1}$, Chloe EDWARDS ${ }^{2}$, Carl HAAS ${ }^{3}$ \\ ${ }^{1}$ PhD Candidate, Ralph Haas Infrastructure and Sensing Analysis Laboratory, University of Waterloo \\ ${ }^{2}$ MASc Student, Ralph Haas Infrastructure and Sensing Analysis Laboratory, University of Waterloo \\ ${ }^{3}$ Professor, Ralph Haas Infrastructure and Sensing Analysis Laboratory, University of Waterloo
}

Submitted 30 November 2019

Revised February 2020

Accepted February 2020

Published July 2020

\section{Corresponding Author}

Christopher Rausch

chris.rausch@uwaterloo.ca

Ralph Haas Infrastructure and Sensing Analysis Laboratory, University of Waterloo 200 University Avenue West Waterloo, ON, Canada N2L 3G1

\section{ABSTRACT}

Dimensional quality plays a key role in project success for modular construction. While approaches exist for reducing rework associated with dimensional variability in traditional construction (i.e., onsite resolution), more proactive approaches must be employed during offsite production of modules. Unfortunately, the stricter dimensional quality demands in modular construction are not yet completely addressed in existing guidelines or studies. As such, contractors often must resort to use of reactive measures to reduce rework. This paper bridges this gap by demonstrating how to implement continuous benchmarking and improvement of dimensional quality by comparing as-built and nominal 3D geometric data across modular construction projects. A case study is presented for two nearly identical modular construction projects, which are carried out in succession. The first project is used to quantify and benchmark key impacts on overall dimensional quality, while strategic improvements are introduced in the second project to improve quality and reduce rework. The results of this study demonstrate how contractors can achieve adequate dimensional quality and reduce rework on successive modular construction projects.

DOI http://doi.org/10.29173/ijic212

Pages 2-21

ISSN 2563-5034

\section{KEYWORDS}

Modular Construction, Dimensional Quality, Laser Scanning, Continuous Improvement, Dimensional Tolerance, Rework Avoidance 


\section{Introduction}

Modular construction practices have been on the rise in the construction industry in recent years [1,2]. The implementation of prefabrication and modularization benefits the industry through improved safety and quality control and lower construction costs [3-5]. Despite this increase in benefits, there is an ongoing discussion in the industry regarding the impacts on structural safety, constructability, aesthetics, and functionality with respect to dimensional quality [6-8]. Often these impacts are observed when modules are assembled or erected on site, and issues with aggregation of components arise. Evidence of non-conformance between components includes misalignment of framing members, unlevelled surfaces, and gaps between structural components, among others [9]. While some of these impacts are purely aesthetic, some impacts could lead to issues of structural safety, thus compromising the integrity of the building structure [3]. Therefore, it is becoming critical to progressively develop an approach for monitoring and addressing sources of variability as they are observed. A unique challenge with modular components compared to conventional construction techniques is the disruption of rework at later stages of the project. Since the majority of components are fabricated and assembled offsite, then transported to site, rework on-site is associated with additional costs, time and safety risks. To date, there are numerous research works surrounding tolerance specification and management in construction [10-13]. However, very few studies to date present real-world data for dimensional quality in modular construction.

This paper presents a case study for benchmarking and continuously improving dimensional quality across two identical modular construction projects, which were completed in succession. The first project was studied in detail, in order to capture and quantify dimensional quality at each of the key construction stages. A laser scanner was used to collect as-built data, which was subsequently assessed using scan-vs-BIM to determine dimensional quality of features, components and assemblies. The overall accumulation of dimensional variability from fabrication, assembly and module handling processes in the first project led to undesirable geometric conditions in the plant and on site (e.g., gaps, clashes, misalignments). Based on these undesirable observations of dimensional quality, improvements were introduced for the second project using Design for Manufacture and Assembly (DfMA) principles and stricter dimensional controls during production. In this way, dimensional quality was effectively benchmarked for the modular fabricator for these projects in order to reduce rework and improve dimensional compliance. This paper contributes to the body of knowledge by presenting real-world data on modular construction assemblies with respect to dimensional quality and provides a clear demonstration of how digital technologies (e.g., laser scanning and deviation analysis) can be used to validate modular process improvements. Specifically, these contributions culminate in a framework that outlines the process for implementing continuous benchmarking and improvement of dimensional quality in modular construction. Validation of this framework is evidenced through the following case study results: a reduction in elastic deflection of modules during production by $83 \%$, elimination of subassembly fit conflicts (altogether), a reduction in structural assembly dimensional variability by $53 \%$ and a reduction in dimensional variability for module tie-in points by $82 \%$.

This paper is organized as follows: Section 2 provides background on dimensional quality, how it can be quantified and how current approaches are used to achieve adequate dimensional quality in modular construction. Section 3 highlights the research approach employed. Section 4 provides a background for the case study. Section 5 outlines the quantification and benchmarking of dimensional quality in the first modular construction project. Section 6 outlines the changes introduced to improve dimensional quality in the second project, and finally, Section 7 provides conclusions from the case study including some brief recommendations.

\section{Background}

Dimensional quality requirements in modular construction

The modular construction industry has its roots in the mid-twentieth century when it was implemented as a means of recovering a deficit of housing and buildings following the second World War. The adverse results of mass-producing prefabricated buildings were poor quality, uniformity, life cycle performance failures, and lack of attention to technical detail. As such, there was a lapse in modular construction techniques, until further benefits of modularization and prefabrication emerged in recent years. This was enabled by step changes in 3D scanning, 3D design, supply chain visibility, collaborative design, project execution, and other advancements. Along with an increase in awareness of site safety and congested urban sites, modular construction practices are being implemented to provide shorter project schedules, lower construction costs, and increased safety and quality control [7]. Although many of the conventional construction issues have been addressed through modularization, several challenges still exist. Based on various studies that evaluate challenges within the modular construction industry $[14,15]$, five of the most prominent risks are listed below:

1. Poor cooperation between numerous interfaces

2. Inappropriate design standards based on stickbuilt practices that are not satisfactory for modular construction

3. Lack of proper management and experience

4. Enormous difficulty obtaining a return on initial investment 
5. Lack of sufficient quality monitoring mechanisms during production processes

A combination of these challenges can often lead to the major issues of dimensional and geometric variability in a modular construction project. When structural components are prefabricated and assembled offsite, there are often challenges with compliance of module geometry once the structure is erected on site. Rework and repairs contribute to delays in project schedule and cost overruns since deviations and misalignments are often identified at later stages of a project when they are more expensive to resolve [16]. Since there is less forgiveness in correcting prefabricated component dimensions, techniques for managing dimensional variability from a proactive standpoint need to be developed and understood by the industry. A drawback to proactive approaches is the significant amount of investment required in early stages of the project [9]. Therefore, a framework that addresses these challenges while optimizing offsite and onsite costs should be applied for quantifying and benchmarking dimensional quality.

To gain an understanding of the overall accumulation of dimensional variability, it is necessary to examine the typical stages of modular construction, including material and manufacturing, sub-assembly, module assembly, transportation to site, and erection on site. Due to the arrangement of steps involved in modular construction, dimensional deviations can develop at an early stage and evolve or propagate throughout the progression of the project. This progression of dimensional variability can often be attributed to a lack of understanding in applying and controlling tolerances during design and construction $[17,18]$. Typically, modular construction projects incorporate interfaces of different materials (e.g., steel, concrete, wood, etc.). This poses a challenge when the tolerances of diverse materials do not follow cohesive guidelines, resulting in potential component misfit or excessive rework. While in conventional construction projects, remedial work can be completed on site, this is not an ideal management technique for modular projects. It is therefore important to find a balance between relaxing and tightening a tolerance such that the product functions as expected without increasing construction cost [19].

There is very limited literature presenting real-world dimensional variability for prefabricated or modular components in construction. The most applicable studies to date only relate to precast concrete beams, columns and wallboards [20]. Other works outlining dimensional quality control requirements for modular construction only provide overall tolerance accumulation limits. For instance, Lawson et al. provide tolerance limits for overall verticality, length and width of modules as 1/500th of each dimension respectively [3]. Similarly, Gorgolewski et al. outline tolerance limits of $+/-10 \mathrm{~mm}$ for every $10 \mathrm{~m}$ wall increments [21]. Lawson and Richards propose overall verticality accumulation limits between stacked modules as $<5 \mathrm{~mm}$ per storey, which cannot exceed 50 $\mathrm{mm}$ for any given modular building [22]. Despite the usefulness of these guidelines, they do not address tolerance limits on subassemblies (i.e., within a given module), nor on production processes themselves. Since there are no comprehensive guidelines or standards provided to classify dimensional variability and its impact on the construction process, numerous resources for specific materials and applications must be referred to in addressing tolerances [23]. For this reason, increasingly, modular construction contractors must rely on internal establishment of product and process tolerances to achieve adequate performance and dimensional quality.

\section{Quantifying dimensional quality}

For determining the dimensional quality of a modular construction project, it is necessary to quantify the magnitude of geometric deviations through each stage of modular construction. Common methods of quantifying geometric dimensions include measuring tapes, laser rangefinders, carpenter levels, digital inclinometers, transits and construction lasers, electronic instruments and laser scanners [10]. Recently, sensing technologies such as global positioning systems (GPS), ultra wide band (UWB) tags, total stations, digital photogrammetry and terrestrial laser scanners can be used for 3D data acquisition and analysis. In the context of prefabricated construction components, laser scanners are currently viewed as the most applicable tool due to high accuracy and rapid data acquisition capabilities. Nahangi and Haas present an approach for automated compliance monitoring of pipe spool fabrication which compares laser-scanned point clouds to as-designed 3D CAD models [16]. The proposed approach, which is also present in many other studies [24-28], consists of preprocessing BIM and 3D sensing, then point cloud registration which aligns the as-designed and as-built point clouds, and lastly condition assessment to evaluate dimensional accuracy of the assemblies.

The comparison of a 3D laser scan of the as-built assembly with the BIM of the as-designed assembly (i.e., referred to as deviation analysis, or scan-vs-BIM), has been shown in many studies to be a very important aspect of ensuring geometric parameters and tolerances are not exceeded during fabrication and assembly $[24,29,30]$. A deviation analysis allows for either direct or indirect dataset comparisons depending on assembly complexity, geometric compatibility, and type of measurements being collected. There are three forms of dataset comparisons in deviation analyses: (1) point-to-point, (2) point-tofeature, and (3) feature-to-feature (Figure 1).

The choice of which form of measurement to use is largely dependent on the comparison in question. 


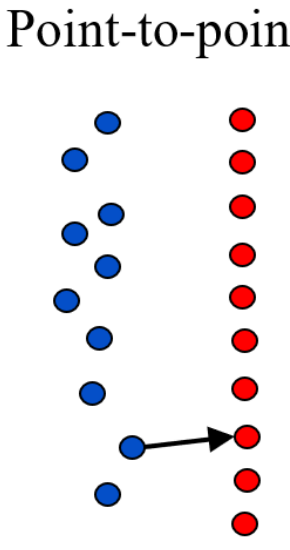

\section{Point-to-feature}

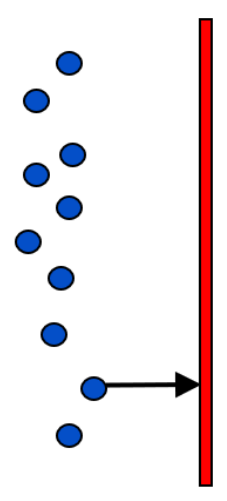

Feature-to-feature

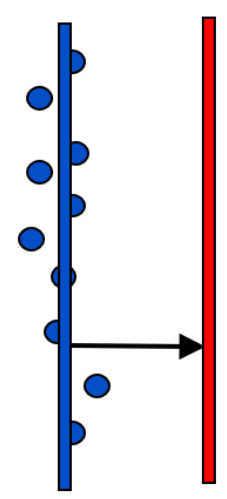

Figure 1. Forms of measurement comparisons used in deviation analysis

For instance, point-to-point measurements are favourable for as-built dataset comparison, whereas point-to-feature or feature-to-feature measurements are useful when using BIM in a deviation analysis. Point-to-feature measurement is also typically used in plane deviation analysis. In this type of analysis, a best-fit plane is created to which as-built data points collected through laser scanning are mapped using their Euclidean distances. Once mapped, a colour is associated with each point to illustrate the distance from the best-fit plane. This method is very suitable to quantify and assess sources of variability in a modular construction project since it can rapidly compare as-built dimensions to corresponding nominal dimensions and provide visualization of deviations. Many contractors rely on this method to verify compliance at key production stages.

Existing research for quantification of dimensional quality in construction focuses primarily on developing automated methods for comparing 3D point clouds to BIM. Reliance on manual methods for quantifying dimensional quality can deter contractors from integrating technology into their workflow, which is one reason why automated methods are favourable. Since automation of analyzing as-built data and subsequent comparison with BIM requires developing bespoke algorithms for specific feature abstraction (i.e., planar features are extracted in a different manner than cylindrical features), most research is focused in key areas of construction objects. For instance, there are distinct workflows developed for automated extraction and evaluation of precast concrete elements [25], cylindrical objects such as pipes [31,32], steel structures [33], and architectural features such as doors, stairs, and walls [34]. Despite the growing availability of these approaches and integration into widely available commercial software, the current quantification process observed in industry is still reliant on manual methods and techniques [35].
Current approaches for achieving adequate dimensional quality

Current approaches for achieving dimensional quality in modular construction can be summarized as design-based approaches and production-based approaches. This section briefly introduces the most common methods employed in each approach based on one of the author's experiences in working with several North American modular construction companies.

\section{Design-based methods}

These methods focus on the development and preservation of highly parametric primitives. In this way, dimensional variability of critical geometric features is identified and resolved through one of two main approaches: (1) explicit parameterization, or (2) parametric objects and rule sets. Since construction assembly configurations range from engineer-to-order systems to standardized product systems [36], the preservation of parametric primitives can be examined in each of these configuration systems.

In highly standardized product systems, parametric objects and rule sets are employed. Parametric object libraries consist of predefined digital building objects, with semantic metadata and adjustable parameters to modify geometry. The use of parametric objects from these easily accessible libraries provides designers with the ability to take basic building blocks and achieve desired customization by modifying intrinsic parameters [37] that are typically set within manufacturable limits from various product suppliers. While parametric objects in these widely available libraries are either industry standards (e.g., I-beams of set sizes) or supplier-specific (e.g., doors within a company catalogue), product developers also create in-house parametric libraries for specific use cases and workflows (e.g., custom steel connections, light-gauge wall framing, etc.). These types 
of bespoke parametric object libraries are often referred to as kits-of-parts [38]. When integrated into a larger platform, these kits of parts along with associated processes, knowledge and relationships are defined as product platforms or configurators. A key benefit of configurators is the holistic control of a product's parameters, which is not solely limited to geometry but also applies to important project-related processes and relationships. Configurators are especially useful for the delivery of highly complex manufactured assemblies, where having process and product-related parameters mapped out in logical relationships is key to reducing conflicts, and poor dimensional quality. The disadvantage to product configurators is the time required to set up the platform and the design restrictions posed by standardization [39]. To address this, ontology-based platforms can be used to automatically link product specifications to manufacturing resources in industrialized construction systems [40,41] which greatly increases the semantics of product configuration platforms.

Outside of standardized product systems, a common approach for achieving adequate dimensional quality in modular construction is the use of Design for Manufacture and Assembly (DfMA). This is a flexible approach that addresses potential dimensional quality constraints through integrated manufacturing and assembly processes [42]. The principles of DfMA that provide efficient management techniques in modular construction include the following [43,44]:

- Collaboration of design engineers, manufacturers, assembly and on-site teams in the early stages of the project to reduce miscommunication and lower risk of rework.

- Observe and resolve challenges faced in past projects. Difficulties from past projects can provide insight into what adjustments are required for improved aggregation and conformance in modular construction.

- Optimize project success through consideration of off-site and on-site construction constraints. Projects that reproduce (i.e., digitize and analyze) on-site conditions during off-site fabrication and assembly typically have a higher degree of conformance when modules are erected on site.

- Integrate standard design attributes and properties. The standardization of components reduces construction costs, potential errors in assembly, and challenges in aggregation on site.

The outcomes of applying DfMA are often projectdependent and are tailored to the specific dimensional quality needs of a given project. Hence, the main objective of DfMA is to facilitate an improvement strategy by integrating design, manufacturing and assembly techniques learned from past experiences to advance project success [45].

\section{Production-based methods}

In addition to the design of highly parametric primitives, geometric control methods during fabrication and assembly ensure that tolerances are met, and dimensional quality maintained. In structural assemblies, proper fit-up between components is critical for ensuring there are no excessive gaps between interfaces. In the event of large gaps between interfaces, joining processes such as welding can introduce secondary stresses due to eccentric loading through the connection which can cause structural safety issues [46]. In modular construction, mechanical fixturing is one of the most common ways for practitioners to ensure the structural system is produced in a controlled (i.e., datum-referenced) manner [9]. Fixturing systems can achieve $1 \mathrm{~mm}$ accuracy for assemblies [47]. While the manufacturing industry employs the use of more permanent jigs, the construction industry often favours the use of reconfigurable fixturing systems in light of mass customization needs as opposed to the large economies of scale seen in manufacturing [48]. In addition to fixturing, 3D vision-based systems are becoming commonplace as tools for guiding the layout process (with a primary focus in practice on "tie-in" points) and validating the final dimensional quality of assemblies [49,50].

Rather than using fixtures for geometric control of nonstructural systems (e.g., MEP, architectural, millwork, etc.), vision-based systems are preferred in modular construction. Fabrication control for non-structural systems includes aspects such as adequate clearances between MEP services, no visual damage or debris on components, brackets installed correctly, flanges connected with the correct fasteners and to the required torque value, and required testing performed prior to commissioning [51]. Given the challenge with use, cost and impracticality of fixturing for these components, vision-based systems such as real-time camera projection, augmented reality, and laser projection are becoming preferred technologies.

\section{Research Method}

The approach for benchmarking and improving dimensional quality in this paper follows the workflow shown in Figure 2. This workflow is intended for use across identical projects, or across projects with identical processes. The purpose of this workflow is to use the quantification of dimensional quality during a modular construction project to establish benchmarks and improvements for subsequent use. The development of this framework follows a popular approach to continuous improvement seen in construction research for addressing 


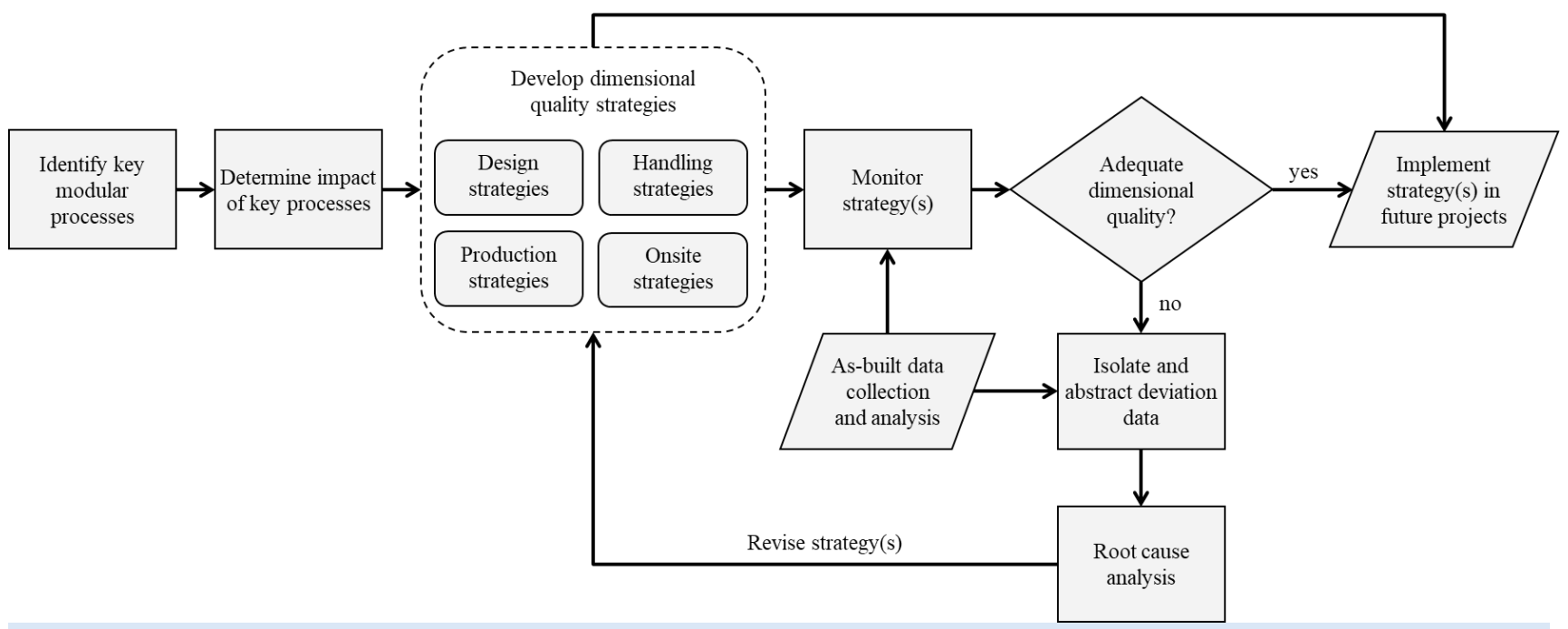

Figure 2. Approach employed for quantifying and benchmarking dimensional quality

rework, labour productivity, quality defects and change orders, among others [52-56].

The first step in this workflow identifies the modular processes that have distinct impacts on dimensional quality. Typical processes include formwork fit-up, assembly layout, cutting, welding, bolting, material handling, hoisting, transporting, etc. The next step determines the specific impact of each process according to existing guidelines for specific materials and processes. Based on concrete and steel construction regulations and standards [57-59], the following critical impact categories are applicable in modular construction:

- Structural safety: this category is considered a primary impact level as it relates to sources of dimensional variability that could alter load paths resulting in instability of the structure. Examples include column eccentricity, location of rebar, reduction in bearing area of components, change in cross-sectional dimensions, etc.

- Constructability: this impact category relates to the level of fit of modular components during aggregation process and erection at the project site. Regardless of the source of variability, component aggregation is compromised when geometric properties of adjoining components are not compatible. This could lead to intensive rework, cost overruns, and delays in the project.

- Aesthetics: this category relates to the quality of the completed project and is typically observed at joints or connections. Dimensional variability at connecting members leads to misalignment of components, unlevelled surfaces, or noticeable deviations that could be interpreted as poor quality.

- Functionality: this category corresponds to the serviceability and general performance of a building and its subsystems. Observations that may fall within this category include windows or doors that are non-functional or piping that fail to meet required slopes for material flow.

The application of targeted strategies at key stages ensures that overall dimensional quality can be managed in a cost-optimal manner. Strategies are grouped into specific categories: design-based, production-based, handling-based, or onsite-based. Design-based strategies aim to achieve adequate dimensional quality through a robust and resilient product design; examples include tolerance design, kit-of-part systems and employing DfMA techniques. Production-based strategies aim to achieve dimensional quality through rigorous project controls during production; examples include 3D visionguided assembly, mechanical fixturing and employing comprehensive quality control checks. Handling-based strategies aim to achieve dimensional quality by controlling both elastic and plastic deflections that result from transportation, handling and erection loads; one example is use of temporary bracing. Finally, onsitebased strategies aim to achieve adequate dimensional quality by bringing modules into proper alignment in order to match intra-module interfaces and module-tofoundation interfaces; one example is the use of a mechanical winch. Ultimately, a range of strategies across the listed categories need to be considered in order to achieve adequate dimensional quality across the project lifecycle. For instance, relying solely on design-based strategies does not ensure modules are produced in a tolerance-compliance manner. Relying solely on onsite strategies (e.g., use of a winch to correct bad geometry) can be averted through better production strategies (e.g., use of mechanical fixturing). For these reasons, the choice of the selected strategies should be determined in a costoptimal holistic manner. 
Scan-vs-BIM is employed as the primary mechanism for quantifying dimensional quality. This research uses commercial software from FARO® called BuildIT Construction. This software boasts continuous construction verification capabilities, with a current focus of development being applied to the prefabrication and modular construction industry [60]. In the authors' experience with various scan-vs-BIM software, FARO® BuildIT Construction is perhaps the most versed for application in modular construction. This is due to its advanced registration capabilities, allowing a user to extract and perform best-fit alignment to custom geometric features, resulting in a more accurate alignment process than the Iterative Closest Point (ICP) algorithm that other software typically employs. In addition, BuildIT Construction was adapted from BuildIT Metrology (which is used in the manufacturing industry) and contains Geometric Dimensioning \& Tolerancing (GD\&T) tools, enabling very granular feature analysis and reporting. For these reasons, FARO ${ }^{\circledR}$ BuildIT Construction was used to compare as-built data from a laser scanner (with an accuracy of $+/-3 \mathrm{~mm}$ ) with BIM data for each component.

In addition to scan-vs-BIM, other analysis mechanisms are relied upon for quantification of dimensional quality. For certain processes where a laser scanner is not a feasible measurement tool, a robotic total station can be used to collect coordinates for quantifying dimensional changes. Since laser scanners provide massive datasets that require abstraction of distinctive features, in some cases, "feature-less" conditions cannot be easily abstracted. For instance, when modules are transported to site, they are often weatherproofed (wrapped with flexible plastic), while the inside is fit-out with drywall, with little to no access to permanent structural features. These surface conditions are challenging for laser scanners to capture, and as such, the use of scan-vs-BIM can produce misleading results. Instead, robotic total stations can be used to measure the coordinates of permanent targets placed on sturdy "feature-less" objects (e.g., walls, tie-in points, etc.). Another way to quantify dimensional quality looks at developing statistical distributions for measurements of features from laser scans. Parameters computed from these statistical distributions provide insight about the extent of tolerance adjustment and variability management required for certain components.

If a given strategy is found to have undesirable dimensional quality, the as-built data collected for monitoring can be used to conduct a root cause analysis. The result of this analysis can be used to improve existing strategies or to develop new ones. For strategies that exhibit adequate dimensional quality, they can be documented and used for continued use across likeprojects and or processes.

\section{Case study background}

Following the research method outlined in Section 3, a case study is presented here outlining how dimensional quality was quantified, benchmarked and improved for two identical modular construction projects. The first project was completed without an extensive understanding of the performance of selected dimensional quality strategies. Upon observing the performance of Project 1, several changes were introduced in Project 2 to improve several aspects of poor dimensional quality that were observed. The changes made in Project 2 were developed after analysis of as-built data collected in Project 1.

In the projects described, a construction company was contracted to build two single-story $805 \mathrm{~m}^{2}$ modular data centers, each with 16 prefabricated steel-framed modules, equipped with a concrete floor. In order to evaluate the dimensional variability, as-built dimensional data was gathered during the following key project stages: (1) fabrication and assembly, (2) temporary support and transportation of modules, and (3) erection of modules at the project site. Gathering data at each of these key project stages provided an indication of how dimensional variability accumulates throughout the lifecycle of a project. Figure 3 illustrates the general layout of the projects discussed in this case study.

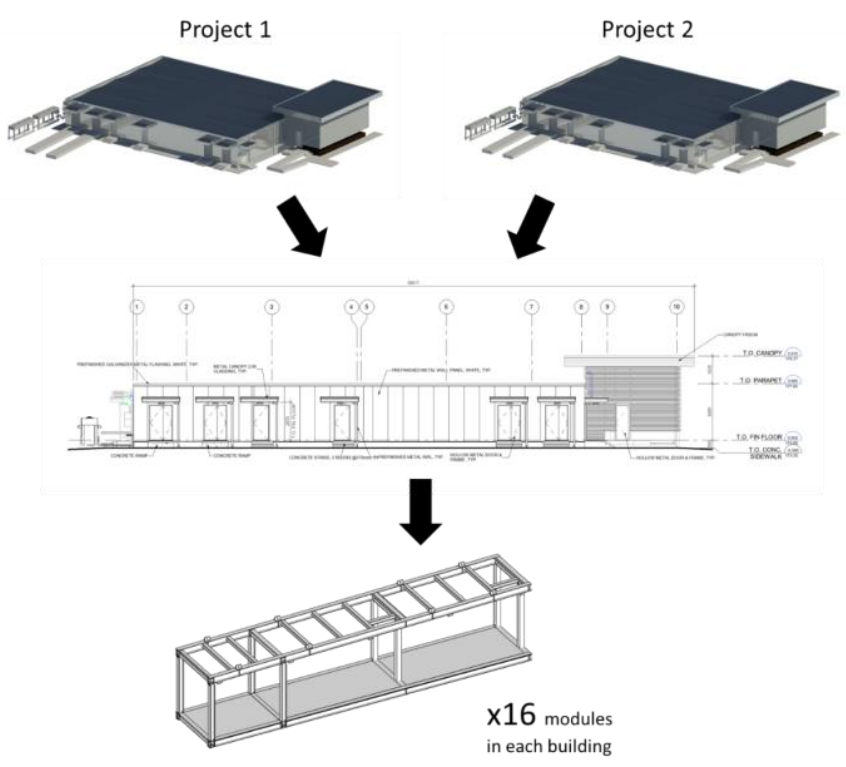

Figure 3. Case study used to demonstrate dimensional variability throughout the lifecycle of a modular construction project

\section{Quantifying dimensional quality in Project 1}

Throughout the key stages listed, a terrestrial laser scanner was used for primary 3D as-built geometric data collection and a robotic total station collected secondary data during the transportation and site-erection stages. 


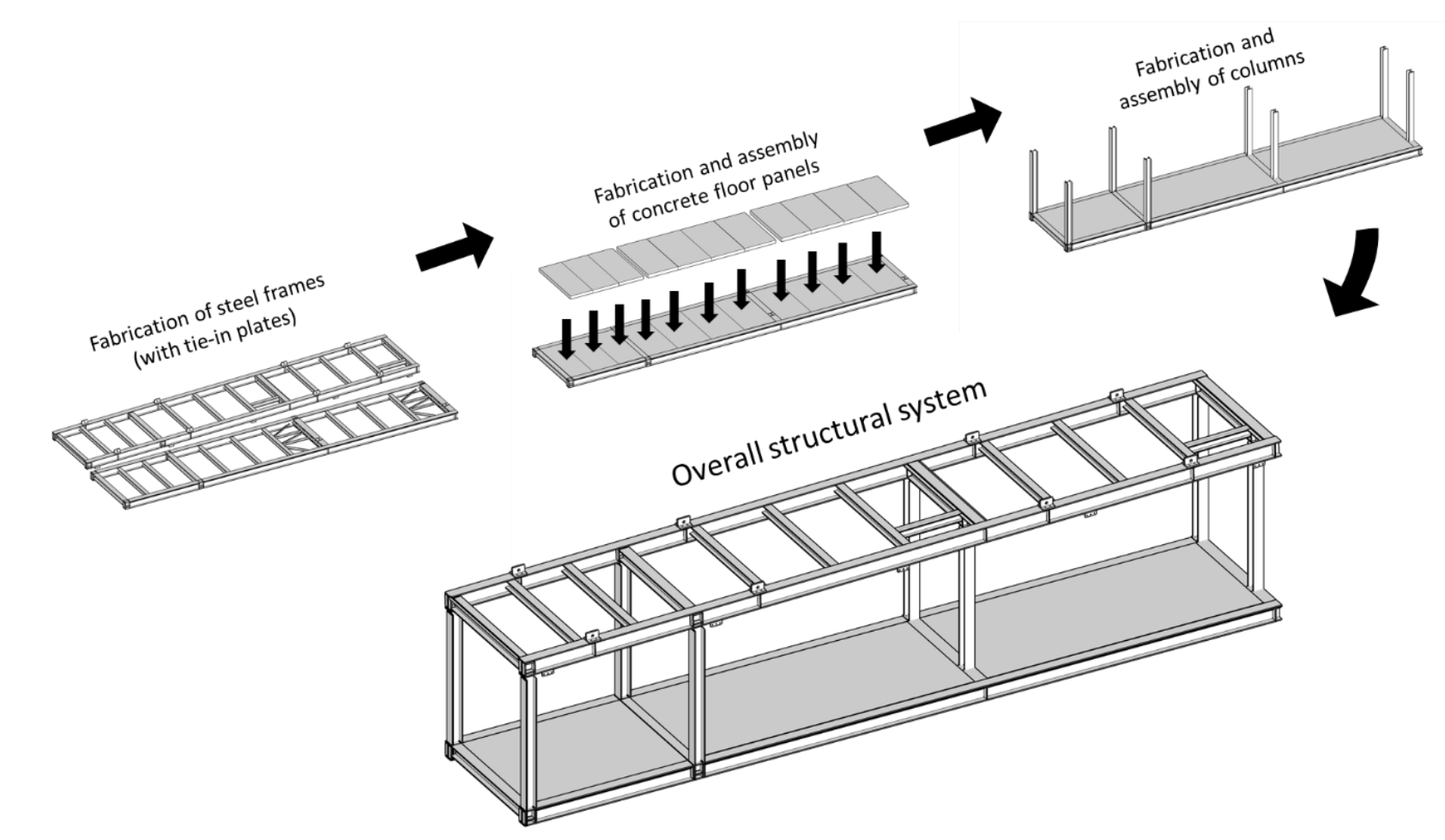

Figure 4. Sequence of structural system fabrication

Stage 1: fabrication of structural system

The fabrication process in Stage 1 of this project included the manufacture and assembly of the floor frame, roof frame, and aggregation of precast concrete panels as illustrated in Figure 4.

\section{Precast concrete panels}

The workflow followed for the precast concrete panels in Project 1 involved: (a) light-gauge steel pan fabrication (used for containing concrete), (b) formwork placement on the shop floor, (c) fit-up of a rebar mesh, (d) concrete pouring and levelling, (e) concrete finishing and screeding. Following this procedure, the concrete panels were stacked until they were placed in the floor frames. The concrete panels were designed with a length of 2,259 $\mathrm{mm}$, a height of $102 \mathrm{~mm}$, and varying width according to the layout of the floor frame. During production, guidance for gap tolerance between the concrete panels and floor frame was $+3 \mathrm{~mm}$ for the width or length of any panel. This tolerance was based on the eight critical dimensional variability types stated in the Precast/Prestressed Concrete Institute Design Handbook (PCI Industry Handbook Committee, 2004). Based on suitability for this case study, the following dimensional analyses were conducted: (1) the overall dimensions of the concrete panels (i.e. length, width, and height), and (2) plane deviation for warping, bowing, and smoothness of the concrete surface.
To evaluate the geometric compatibility of the concrete panels, a point cloud was obtained for the overall panel stack which was then used to manually extract individual panel dimensions. Since the line-of-sight during scanning was limited to the edges of the concrete panels, there were occlusions within the centre of each panel. To quantify the overall dimensions of the concrete panels (Analysis 1), linear dimensions were manually extracted from the outer edges of the point cloud corresponding to an average height $(\mathrm{Z})$, width $(\mathrm{X})$ and length $(\mathrm{Y})$. Results from this analysis indicated that the as-built panel dimensions were typically less than the as-designed nominal dimensions. Based on this data, histograms were created to statistically evaluate the dimensional variability as shown in Figure 5.

Analysis found that the data was normally distributed. This was verified using chi-square goodness-of-fit tests according to the formula

$$
\chi^{2}=\sum_{i}^{k} \frac{(O i-E i)^{2}}{E i}
$$

where $O i$ is the observed frequency for bin $i$ and $E i$ is the expected frequency for bin $i$ which is found by

$$
E i=N(F(Y u)-F(Y l))
$$



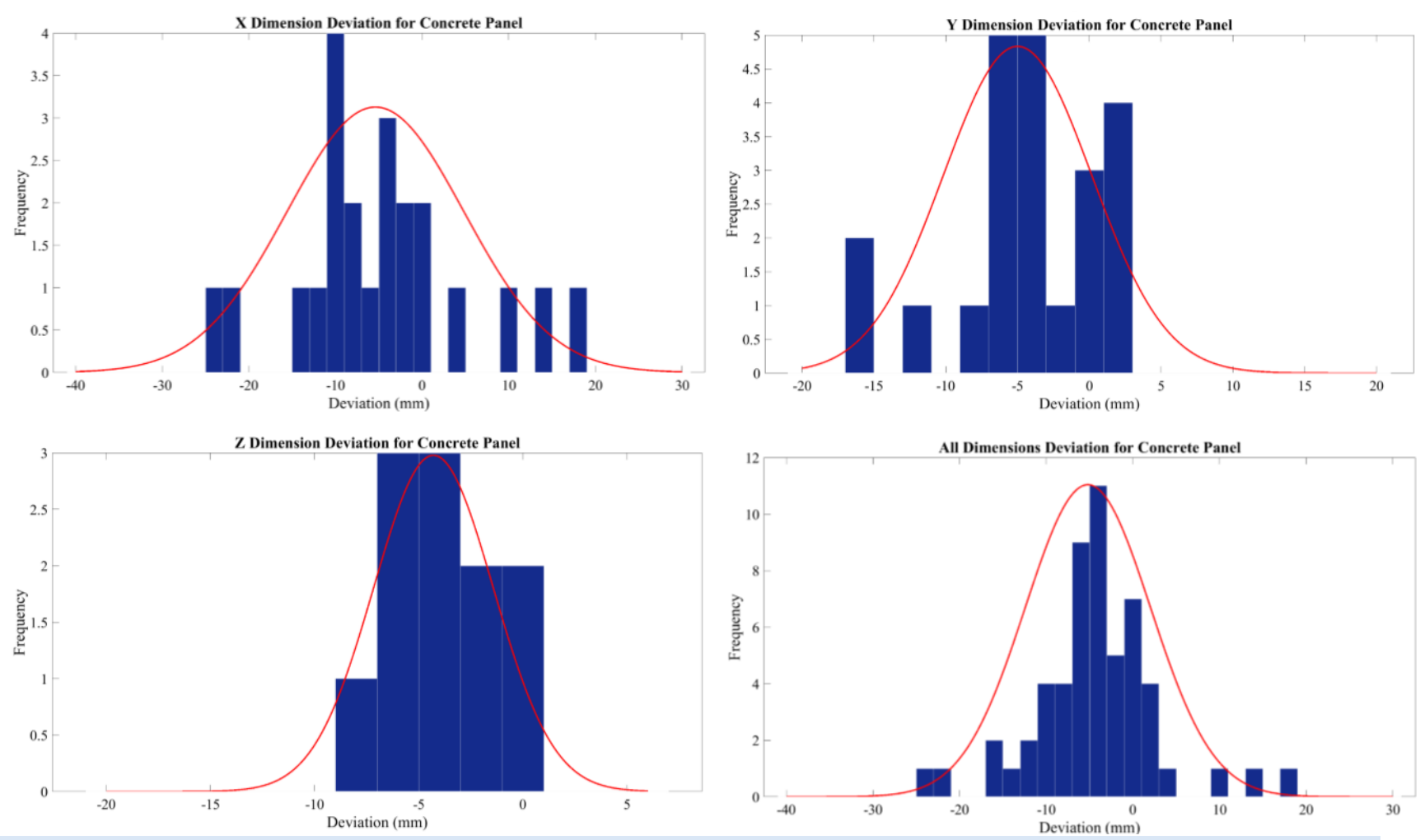

Figure 5. Histograms based on a comparison of as-built and as-designed dimensions of precast concrete panels. Histograms are overlaid with best-fit standard normal distributions

where $F$ is the cumulative distribution function, $Y u$ is the upper limit for class $I, Y l$ is the lower limit for class $i$, and $N$ is the sample size for a given dimension. Although the significance levels for each set of dimensions resulted in poor significance levels $(<25 \%$ significance of the null hypothesis), analysis of all dimensions combined produced a statistically significant result for the normal distribution ( $0.2 \%$ significance of the null hypothesis). It should be noted that fitting this data with the normal distribution also matches observations found in other research of precast concrete assemblies [20]. Based on the histograms created from the dimensional data (Analysis 1 ), it was found that the variability of the concrete panel overall dimensions followed a normal distribution with a mean of $-5.0 \mathrm{~mm}$ and a standard deviation of $7.1 \mathrm{~mm}$.

The second analysis conducted on the precast concrete panels was evaluation of plane deviation in terms of warping, bowing, and surface smoothness. Figure 6 shows the point cloud of the stacked panels alongside a single panel illustrating the plane deviations on the top surface.

As described in Analysis 1, the lack of data available for the centre of the concrete panel resulted in partially inconclusive results about the dimensional variabilities of interest. Despite this, it was still possible to obtain surface data for the top of the panels. According to dimensional quality standards, the tolerances provided for warping, bowing, and smoothness of a panel of these dimensions are $13.3 \mathrm{~mm}, 7.1 \mathrm{~mm}$, and $6.4 \mathrm{~mm}$, respectively. In this analysis the panel deviations corresponding to warping, bowing, and smoothness deviations were $5 \mathrm{~mm}, 5 \mathrm{~mm}$, and $6 \mathrm{~mm}$, respectively. Although the deviations were within the recommended tolerances, it is worthwhile to note that the smoothness of the panel exhibited the highest deviation yet had the strictest tolerance for plane deviation analysis. This is likely due to the size of the panels in this case study, which are typically much smaller than most precast concrete members (e.g., beams and floors in buildings).

\section{Fabrication of steel floor and roof frames}

The steel standardized frames for this project were outsourced by the construction company. Custom bracing was then added to the steel frames using a BLUCO fixturing table for layout and support during welding. Cutting, welding, measuring, fit-up and grinding processes were observed for their impact on overall dimensional quality. Provision for tolerances for the steel frames came from the AISC Code of Standard Practice for Steel Buildings and Bridges which recommended the following critical fabrication tolerances criteria: (1) straightness, (2) variation in length, (3) camber, and (4) mill tolerances [61]. The following analyses were conducted based on relevance for this case study: 


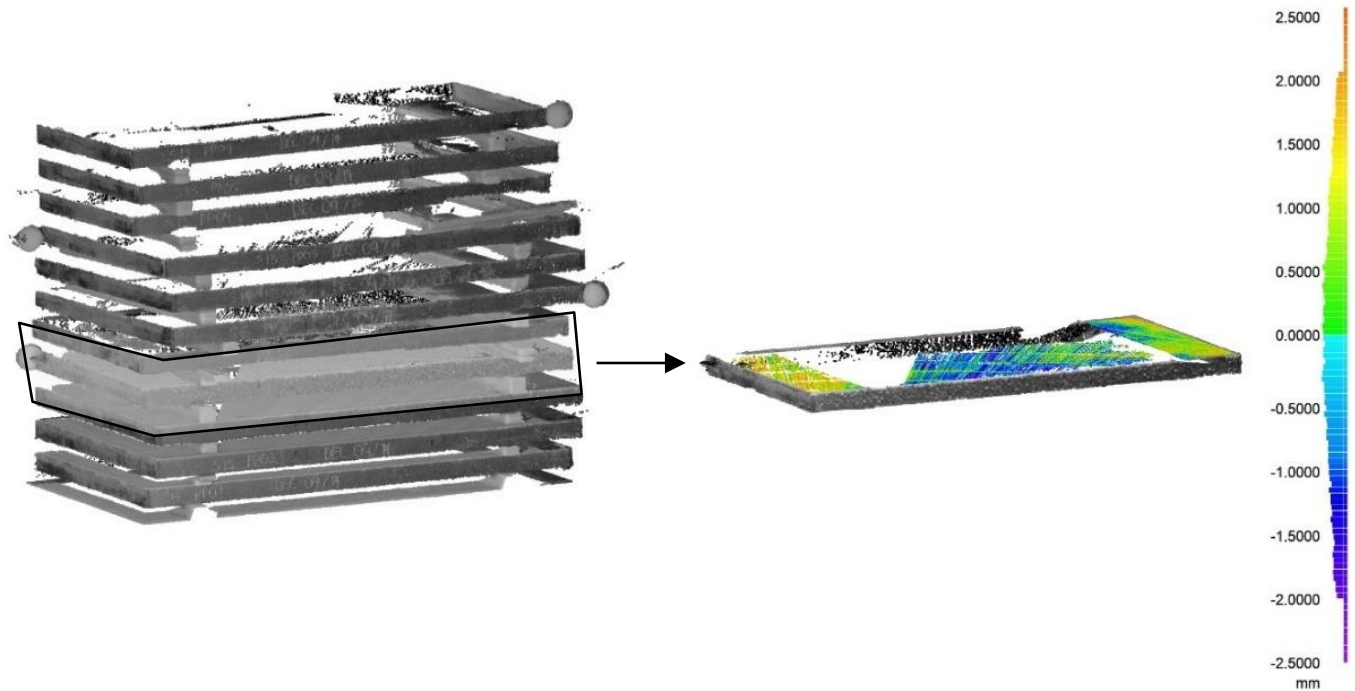

Figure 6. Plane deviation analysis of a precast concrete panel extracted from a scan of the stacked panels

1. Quantifying dimensional variability of the floor frame 'slots' used to place the precast concrete panels. Deviation of these dimensions has an impact the internal aggregation (i.e., panel fit within the floor frame).

2. Overall geometry of frames in terms of warping or bowing. Deviations of this type have an impact on external aggregation (i.e., module-tomodule aggregation).

Similar to the analysis of the precast concrete panels, the dimensional quality of the floor frame slots was analyzed by manually extracting measurements from a laser scan of the frame slot. Based on this data, histograms were created to evaluate the distribution of dimensional deviations in the same format as the data shown in Figure 5. The deviations of the slot as-built dimensions follow a normal distribution with a significance level equal to $11.4 \%$. This was accepted as the best-fit distribution, despite having a significance level greater than 5\% (the typical limit for significance), since other probability distributions had higher significance levels in comparison. As a result, the as-built data for the floor frame slot dimensions are normally distributed with a mean of $2.17 \mathrm{~mm}$ and a standard deviation of $8.31 \mathrm{~mm}$.

The second analysis for the frames consisted of comparing as-built data from a laser scanner with the asdesigned BIM. The result of conducting this analysis for numerous frames resulted in typical deviation patterns shown in Figure 7. As shown in this figure, there are considerable vertical distortions in the frame (ranging from $-11 \mathrm{~mm}$ to $+15 \mathrm{~mm}$ ) which lead to poor dimensional quality.

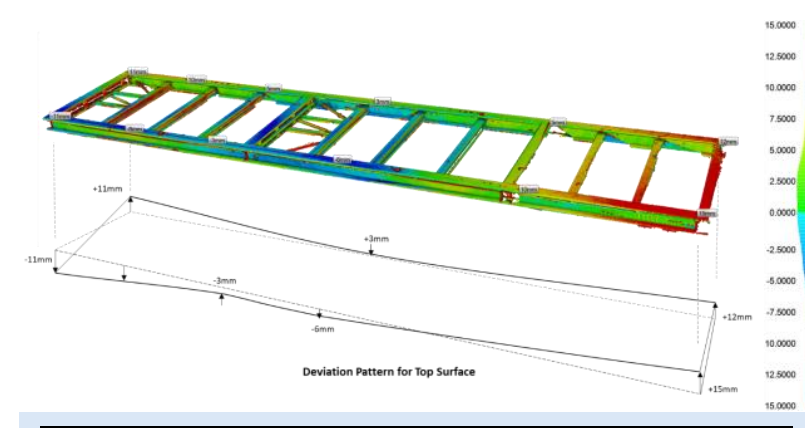

Figure 7. Scan-vs-BIM analysis to reveal deviations in steel frame fabrication

Assembly of structural system

The key processes involved in structural assembly included installation of precast concrete panels into the floor frame, installation of columns, and installation of the roof frame on the columns. The processes affecting dimensional quality derive mainly from fit-up and welding. Thus, the following analyses were conducted: (1) precast concrete panel and floor frame dimensional comparison for fit compliance, (2) overall geometry of assembled module, and (3) position and orientation of tiein plates for compliance of assembly. An important dimensional quality factor of the overall module is the fit of the precast concrete panels in the floor frame slots. While the contractor did not disclose the exact number of panel misfit occurrences, they noted that misalignment and panel misfit was a significant issue during fabrication. Using the raw data and best-fit probability distributions for the data, the following approaches can be used to quantify the degree of non-compliance:

1. One-to-one comparison of each panel dimension to each corresponding frame slot dimension resulted in a non-compliance of 7\% (i.e., 4 of 55 dimensions were non-compliant). 
2. One-to-one comparison of each panel to each frame slot, and if any dimension within each comparison is non-compliant, the whole panel is non-compliant since it requires some form of rework. In this case, 4 of the panels had at least one dimension that exceeded the corresponding frame slot dimension. Therefore, non-compliance according to this calculation is equal to $36 \%$ (i.e., 4 of 11 panels require rework).

3. Comparison of probability distributions created for the panels $(\mathrm{N}(-5.0,7.1))$ and floor frame slots $(\mathrm{N}(2.17,8.31))$ resulted in a non-compliance of $26 \%$.

The third approach is based on comparing the intersection of the probability distributions created for the panels and frame slots. This approach is analogous to computing the probability of failure in structural reliability theory where failure occurs if the panel is greater than the frame. The compliance rate was therefore computed by calculating a reliability index of the two distributions as follows:

$\beta=\frac{\mu_{\text {frame }}-\mu_{\text {panel }}}{\sqrt{\sigma_{\text {frame }}^{2}+\sigma_{\text {panel }}^{2}}} \rightarrow \mathrm{P}_{\text {non-compliance }}=\Phi(-\beta)$

where $\beta$ is the reliability index, $\Phi$ is the cumulative distribution function for the standard normal distribution, $\mu$ is the mean and $\sigma$ is the standard deviation. The integration of the probability distribution function for panel dimensional variability with the cumulative distribution function for frame dimensional variability is shown in Figure 8.

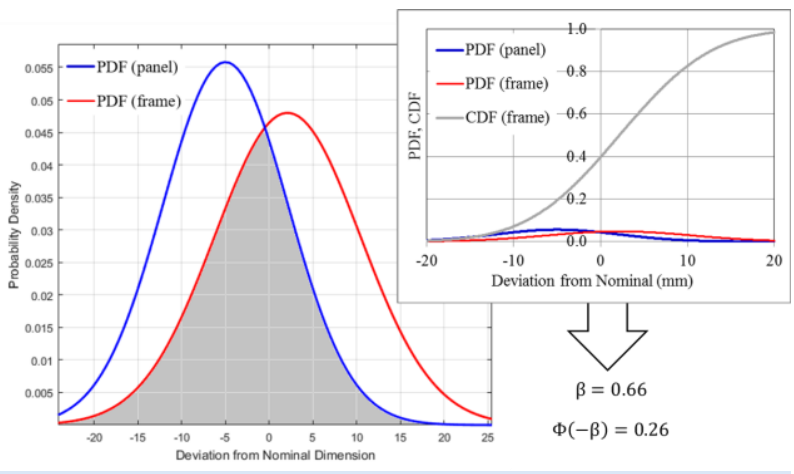

Figure 8. Comparison of probability distributions for precast concrete panels

The second analysis evaluated the extent of dimensional variability of the assembled module. Once assembled, the module was supported on a BLUCO framing table and scanned for deviation analysis. An overall-best fit approach was taken for this analysis to compare the point cloud dimensions. The results of this analysis are shown in Figure 9, with deviations ranging from $-8 \mathrm{~mm}$ to 18 $\mathrm{mm}$.

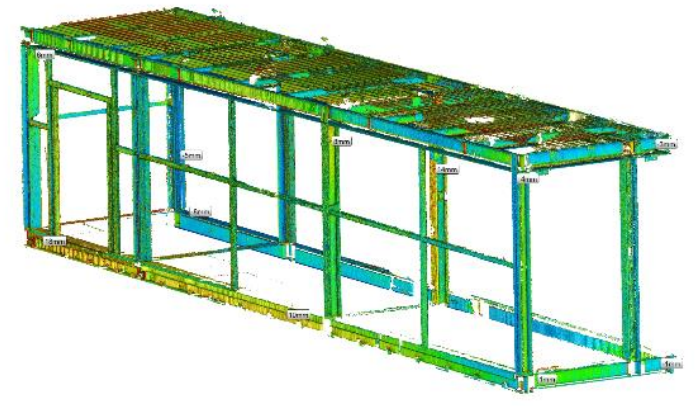

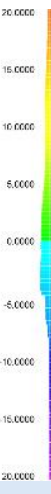

Figure 9. Deviation analysis of assembled module supported by a BLUCO framing table

The column dimensions were also analyzed to determine compliance of the assembled module. By comparing the point cloud measurements of a sample column to the corresponding nominal as-designed dimensions a form deviation of approximately 4 to $5 \mathrm{~mm}$ (from welding) was found. This source of deviation may impact assembly on site as it would cause slight distortion of the module thus causing misalignment when erected on site.

Lastly, the position and orientation of tie-in plates were analyzed since they contribute to the compatibility of module-to-module assembly. A plane was fit the nominal surfaces of the tie-in plates, and deviations obtained to indicate the amount of out-of-plane protrusion (i.e., interference with adjacent module). The magnitude of these deviations ranges from $+6 \mathrm{~mm}$ to $+17 \mathrm{~mm}$ as shown in Figure 10. The fact that every tie-in plate protruded away from the module indicates that the nominal gap between modules is violated, therefore causing potential conflicts between adjacent modules during erection on site.

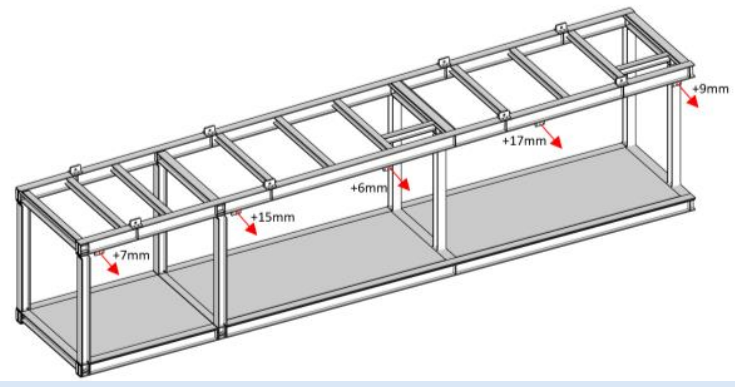

Figure 10. Dimensional quality observed for out-ofplane deviations of tie-in plates

Stage 2: Transportation and handling of modules

During fabrication, the frames and assembled modules experienced two temporary support conditions: a BLUCO framing table used for fit-up and assembly, and four corner supports on the shop floor during production and 

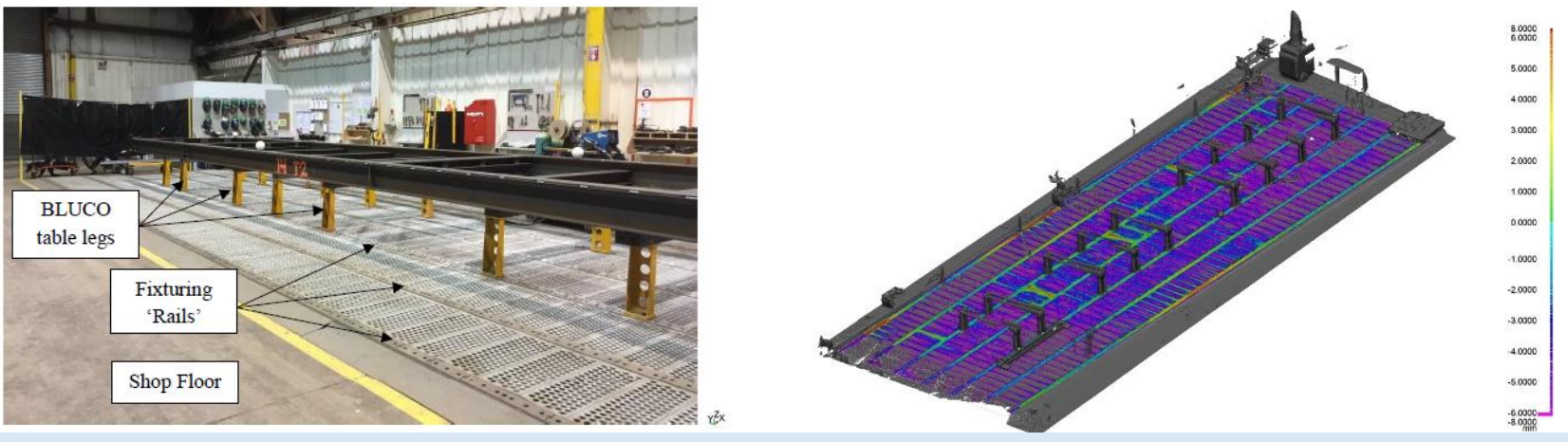

Figure 11. Plane deviation analysis results for BLUCO framing table

installation of subsystems (e.g., MEP work within and between modules). Analysis of the two temporary supports demonstrate how the temporary supports cause elastic changes to the overall module that have an impact on dimensional quality. Results of a plane analysis conducted on the BLUCO framing table showed a bowing pattern of the table rails in which the centre was approximately $7 \mathrm{~mm}$ lower than the left edge and 1 to 6 $\mathrm{mm}$ lower than the right edge. A diagram showing the BLUCO framing table components and the results of the analysis are shown in Figure 11.

The importance of conducting this analysis was to determine how planar the framing table was during the fabrication process (i.e., whether it had angular deviations of $0^{\circ}$ ). The bowing pattern in the rails of the BLUCO table indicate that levelness deviations in the overall framing table system need to be accounted for when evaluating the variability of the assembled modules.

Once fabrication of the structural steel assemblies was complete, modules were hoisted off the BLUCO fixturing table and placed on four temporary 'cribbing' supports on the shop floor. The intention of placing the modules on four corner supports was an attempt to reduce the large deviations of the shop floor. Ensuring modules were level on the shop floor was deemed important for the correct alignment of component installation between modules (i.e., door frames, MEP components, etc.). Although the variability of the floor was reduced from $40 \mathrm{~mm}$ to $14 \mathrm{~mm}$ by using four corner supports, the large weight of modules caused significant deflections in the floor. In this way, the strategy of reducing variability from the shop floor was actually exacerbated by only using four corner supports, resulting in midspan deflections up to $30 \mathrm{~mm}$ as compared to only $5 \mathrm{~mm}$ of deflection when supported on the BLUCO fixturing table (Figure 12).

During transportation of modules, a total station was necessary to use for as-built data collection since weatherproofing of the module and other finishes interfered with gathering surface data by laser scans. As such, 24 permanent targets were placed on exposed steel along the interior of the module to measure dimensions before and after transportation. This analysis showed a permanent deflection of the structure along its length of approximately $3 \mathrm{~mm}$. Since the accuracy of the data obtained from the total station was approximately $2 \mathrm{~mm}$, the amount of plastic deformation caused by transportation was deemed inconsequential to overall dimensional quality. However, as a result of the transportation loads, minor drywall cracking was noted by the contractor, which had to be fixed on site.

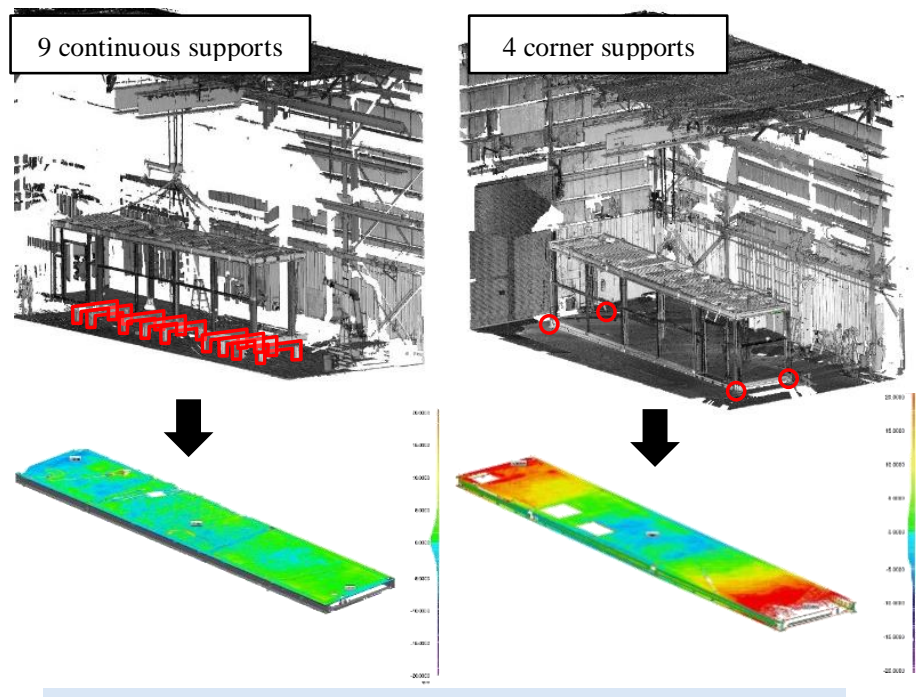

Figure 12. Plane deviation analysis on module floor when supported by nine continuous BLUCO framing table supports (left) and four corner supports (right)

Stage 3: Erection of modules at the project site

In the final stage of this project, dimensional variability corresponding to erection processes was evaluated using a total station in place of a laser scanner due to project logistics and feasibility. Eight targets were placed at accessible key locations along the end of the module and assessed before transportation and after final erection on site. The relative positions of these targets included the 3 $\mathrm{mm}$ deviation observed in the transportation stage, thus resulting in a deviation of approximately $4 \mathrm{~mm}$ due to 
erection loading. Again, due to the accuracy of employing this total station, erection loads on overall dimensional quality was deemed inconsequential.

Summary of dimensional quality observed in Project 1 Once the modules were erected on site, the accumulation of dimensional variability was evident through misalignment and large gaps between module interfaces and tie-in points. These gaps were as large as $50 \mathrm{~mm}$. In addition, several column misalignments were observed, which ranged up to $20 \mathrm{~mm}$. As a result of these observations, the dimensional quality was deemed to be deficient, with root causes tracing back to various sources during fabrication and assembly (Table 1). Based on these values, the critical impacts on dimensional quality derive from assembly of concrete panels with floor frame and midspan deflection at temporary supports. This reflects the main observations noted by the contractor, who reported several challenges with assembly of concrete panels and installation of components between modules. In addition, the accumulation of large variability at tie-in plates was deemed to be traced to insufficient controls during production. As such, several changes were introduced in Project 2 in order to improve overall dimensional quality.

\section{Improving dimensional quality in Project 2}

Project 2 of this case study consisted of the same modular layout with certain changes based on the observed sources of dimensional variability in Project 1 . The three modified strategies for achieving improved dimensional quality in Project 2 were use of Design for Manufacture and Assembly (DfMA), improved temporary supports during production and increased dimensional control for fabrication of the steel assemblies. The basis for revising the dimensional control strategies stemmed from a series of roundtable discussions with representatives from the contractor and the research team (the authors of this paper). The authors conducted the analyses shown in this paper, and based on the results, deviations and potential solutions were presented to the contractor. The decision to use cast-in-place versus pre-cast concrete was decided upon by the contractor management team prior to the dimensional quality issues that occurred since there were difficulties with production that necessitated the switch to cast-in-place.

Table 1. Summary of critical sources of dimensional variability and corresponding impacts to overall structural system

\begin{tabular}{|c|c|c|}
\hline $\begin{array}{c}\text { Construction } \\
\text { process }\end{array}$ & Largest deviations observed & Impact on dimensional quality \\
\hline $\begin{array}{l}\text { Fabrication } \\
\text { of precast concrete } \\
\text { panels }\end{array}$ & $\begin{array}{l}\text { - Warping: } 5 \mathrm{~mm} \\
\text { - Bowing: } 5 \mathrm{~mm} \\
\text { - Smoothness: } 6 \mathrm{~mm}\end{array}$ & $\begin{array}{l}\text { Warping, bowing, and smoothness impact the } \\
\text { geometrical compatibility of panels with the floor } \\
\text { frame. Aesthetics and serviceability are also } \\
\text { impacted depending on extent of variability. }\end{array}$ \\
\hline $\begin{array}{l}\text { Fabrication of floor } \\
\text { and roof frames }\end{array}$ & $\begin{array}{l}\text { - } \text { Bowing: } 17 \mathrm{~mm} \\
\text { - } \text { Tie-in plate position: } \\
\text { - } 5 \mathrm{~mm}\end{array}$ & $\begin{array}{l}\text { If steel frame dimensions are too large, concrete } \\
\text { panels will not fit. If tie-in plates are not in correct } \\
\text { position, modules cannot be connected on site. } \\
\text { Aesthetics are also impacted if gaps are present. }\end{array}$ \\
\hline $\begin{array}{l}\text { Assembly of } \\
\text { structural system }\end{array}$ & $\begin{array}{l}\text { - Overall assembly deviations: } 18 \mathrm{~mm} \\
\text { - Tie-in plate position out-of-plane: } 17 \mathrm{~mm}\end{array}$ & $\begin{array}{l}\text { Aggregation is the critical impact when conducting } \\
\text { non-compliance tests for dimensions, however if } \\
\text { gaps are large enough, the aesthetics of the system } \\
\text { are also impacted. }\end{array}$ \\
\hline $\begin{array}{l}\text { Temporary support } \\
\text { conditions }\end{array}$ & $\begin{array}{l}\text { - BLUCO framing table levelness: } 9 \mathrm{~mm} \\
\text { along length } \\
\text { - Shop floor levelness: } 30 \mathrm{~mm} \text { across } 18 \mathrm{~m} \\
\text { by } 5 \mathrm{~m} \text { area } \\
\text { - Cribbing elevation deviations: } 8 \mathrm{~mm} \\
\text { - Elastic deflection of module: } 30 \mathrm{~mm} \text { at } \\
\text { midspan }\end{array}$ & $\begin{array}{l}\text { Deviations in framing table impact accuracy of fit- } \\
\text { up processes. Modules can elastically distort if } \\
\text { placed directly on the shop floor or if placed only at } \\
\text { the } 4 \text { corner supports (if cribbing is elevated } \\
\text { significantly off the shop floor). Geometric } \\
\text { response of structure to loads can impact } \\
\text { aggregation of sub-systems if fit-up in plant and } \\
\text { final onsite conditions do not match. }\end{array}$ \\
\hline $\begin{array}{l}\text { Transportation and } \\
\text { Handling Loads }\end{array}$ & - Overall assembly deviation: $3 \mathrm{~mm}$ & $\begin{array}{l}\text { Small elastic deflections do not significantly impact } \\
\text { the module or structure but can cause drywall } \\
\text { cracking. Small plastic deflections do contribute to } \\
\text { overall accumulation of variability. }\end{array}$ \\
\hline $\begin{array}{l}\text { Erection at Project } \\
\text { Site }\end{array}$ & - Overall assembly deviation: $4 \mathrm{~mm}$ & $\begin{array}{l}\text { Small elastic deflections do not significantly impact } \\
\text { the module or structure but can cause drywall } \\
\text { cracking. Small plastic deflections do contribute to } \\
\text { overall accumulation of variability. }\end{array}$ \\
\hline
\end{tabular}


However, this decision was also posited by the research team as a concurrent dimensional quality strategy according to the principles of DfMA. The decision to add additional cribbing was a heuristic solution suggested by the research team based on the large midspan deflection experienced. Finally, improving dimensional controls for the welding process of the structural system was developed by the contractor in a quasi fuzzy logic manner (e.g., more measurements are required using higher accuracy devices). Rather than conducting a comprehensive cost analysis to determine optimal revisions to dimensional quality strategies, revisions were introduced and implemented in a heuristic manner. The impact of these revised strategies is discussed below.

\section{Use of DfMA to improve dimensional quality}

According to Yuan et al., concepts of DfMA that are applicable to the construction industry include minimization of precast component types, use of standard off-the-shelf products, minimization of connection types/quantity and use of mistake-proof designs [43]. In this way, the approach of how the floor was fabricated and assembled in Project 2 was improved in order to avoid the number of additional aggregation processes (Figure 13). As discussed, Project 1 incorporated concrete panels that were manufactured prior to being assembled into the floor frame. This resulted in a significant percentage of rework $(\sim 36 \%)$ required by the contractor to ensure the panels fit properly. This challenge was addressed in Project 2 by placing formwork, light-gage steel pans and rebar meshes directly in the floor frame and pouring the concrete after the frame assembly. As a result, the probability of rework associated with panel fit was eliminated (i.e., 0\%). In addition to improving the aggregation process, this approach also ensured that the concrete floor did not protrude out of the steel frame, thereby improving the aesthetics and functionality of the floor (i.e., the $\mathrm{Z}$ dimension was controlled).

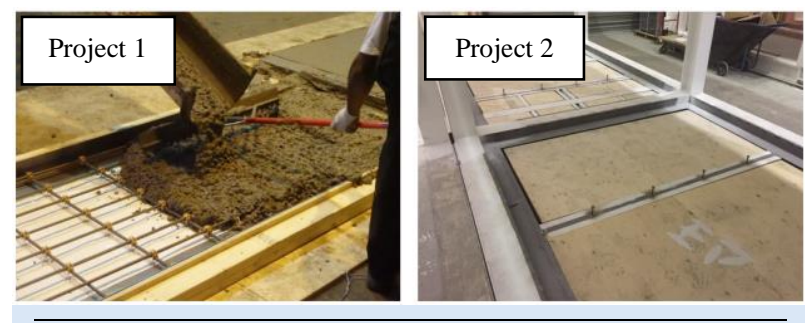

Figure 13. Precast concrete panels to be fit into floor frame in Project 1 (left) compared to formwork fitted in floor frame then pouring concrete directly in Project 2 (right)

\section{Improved temporary supports during production}

Considering the conflicts faced for components installed between modules, the temporary support conditions during production (after steel frame fabrication was completed) were changed in order to reduce the large midspan deflection of modules. Compared to the four corner 'cribbing' supports in Project 1, two additional cribbing supports were added at the center of the module to restrain the midspan deflection in Project 2. This resulted in a decrease of midspan deflection of approximately $25 \mathrm{~mm}$ (from $30 \mathrm{~mm}$ to $5 \mathrm{~mm}$ ). In general, in order to reduce component misfit between modules during fabrication, it is important to represent the final onsite conditions during production. For these projects, four helical piers were used on site to support each side of a module (eight piers per module in total), which were vertically aligned to an accuracy of $+/-2 \mathrm{~mm}$. While these conditions were not exactly replicated during production on the shop floor, the overall variability reduction of 40 $\mathrm{mm}$ from the shop floor to $14 \mathrm{~mm}$ of six cribbing supports (Figure 14) significantly improved the fit-up of components between modules on site.

\section{Shop Floor Plane Analysis}
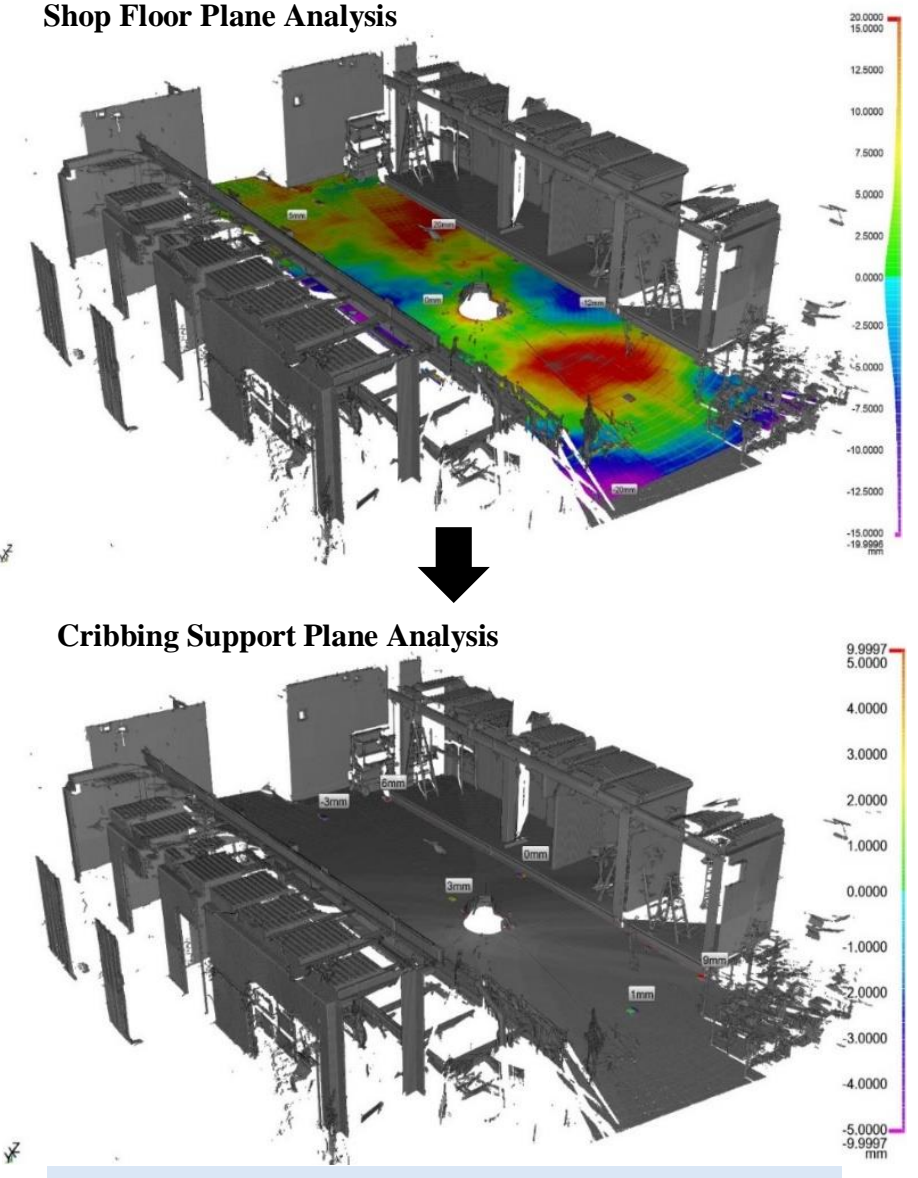

Figure 14. Demonstration of how shop floor variability is reduced through use of 6 cribbing supports

Improved dimensional control during fabrication of steel assemblies

Finally, to address the large dimensional variability experienced in Project 1 related to the fabrication of steel assemblies, Project 2 included a stricter dimensional control strategy during production. While a fixture table 
was employed for layout of floor and roof frames, Project 1 did not consider an effective approach for 'plumbing' columns. This contributed to the bowing and warping found in the position of the roof frame relative to the floor frame. As such, Project 2 involved a much stricter approach to ensure column verticality and employed the use a laser meter to correctly plumb columns. As a result, the overall deviations of the steel assembly were reduced from a maximum of $18 \mathrm{~mm}$ to $11 \mathrm{~mm}$, with noticeably less average deviation as seen in Figure 15. Furthermore, deviations of the tie-in plates were significantly reduced from a maximum out-of-plane deviation of $17 \mathrm{~mm}$ to 3 $\mathrm{mm}$. Collectively, the impact of stricter dimensional control during production led to the greatest changes in module-to-module connections on site, thereby significantly improving dimensional quality.

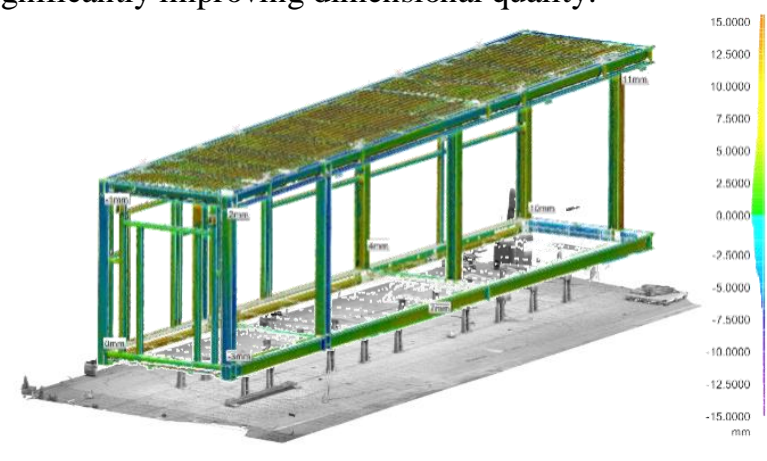

Figure 15. Overall dimensional variability in the steel assembly for Project 2
Results of improved dimensional quality strategies

Evidently, the changes made to the fabrication processes in Project 2 considerably improved dimensional quality compared with Project 1. In Project 2, fewer framing members were misaligned, connection plates lined up as intended, and the interfaces at columns were mostly level (Figure 16). These improvements were made by modifying production processes and incorporating the concept of DfMA. Through reduction of components in the flooring system, the concrete flooring was compatible with the steel frames without gaps or uneven surfaces. Additional supports also reduced the midspan deflection while maintaining similar conditions with the project site. Finally, the use of stricter dimensional control during fabrication of the steel assembly contributed to better aggregation of modules on site. A summary of the deviations observed and improvements made to dimensional quality in Project 2 are outlined in Table 2. Since the deviations from transportation and erection loads were low in Project 1 (3 $\mathrm{mm}$ and $4 \mathrm{~mm}$ respectively), they were not directly measured in Project 2. However, deviations associated with the structural system as a whole, temporary support conditions and final module interface gaps on site are reported. In conclusion, this case study demonstrates how a framework that focuses on identification and evaluation of dimensional variability sources throughout each stage of a project's lifecycle can improve the overall dimensional quality of successive modular construction projects and processes.

Table 2. Summary of deviations observed, and improvements made to the dimensional quality in Project 2

\begin{tabular}{|c|c|}
\hline Construction process & Largest deviations observed \\
\hline $\begin{array}{l}\text { Fabrication } \\
\text { of concrete floor } \\
\text { (cast-in-place) }\end{array}$ & $\begin{array}{l}\text { - Warping: } 0 \mathrm{~mm} \\
\text { - Bowing: } 0 \mathrm{~mm}\end{array}$ \\
\hline $\begin{array}{l}\text { Fabrication of floor } \\
\text { and roof frames }\end{array}$ & - Bowing: $8 \mathrm{~mm}$ \\
\hline $\begin{array}{l}\text { Assembly of structural } \\
\text { system }\end{array}$ & $\begin{array}{l}\text { - Overall assembly deviations: } 11 \mathrm{~mm} \\
\text { - Tie-in plate position out-of-plane: } 3 \mathrm{~mm}\end{array}$ \\
\hline
\end{tabular}

Improvement from revised strategy

Choosing the cast the concrete floor in place absolved dimensional conflicts from warping and bowing of (previous) pre-cast concrete panels. Stricter dimensional controls stemming from laser meter layout and improved fixturing resulted in a decrease in frame bowing from $17 \mathrm{~mm}$ to $8 \mathrm{~mm}$. The use of stricter dimensional controls during production reduced overall assembly deviations from $18 \mathrm{~mm}$ to $11 \mathrm{~mm}$. More significantly, stricter controls for the layout and welding of tie-in plates reduced the maximum overall out-of-plane deviations from $17 \mathrm{~mm}$ to $3 \mathrm{~mm}$.

The use of cribbing at the module midspan reduced the deflection from $30 \mathrm{~mm}$ to $5 \mathrm{~mm}$. Interesting, while the vertical deviations of cribbing for Project 2 were larger than Project 1 (14 $\mathrm{mm}$ compared to $8 \mathrm{~mm}$ ), the inclusion of additional cribbing at the midspan had a greater influence on controlling vertical deviations of modules during production.

Whereas large gaps $(50 \mathrm{~mm})$ between module interfaces occurred in Project 1, the revised strategies in Project 2 eliminated these interface gaps altogether $(0 \mathrm{~mm})$. 


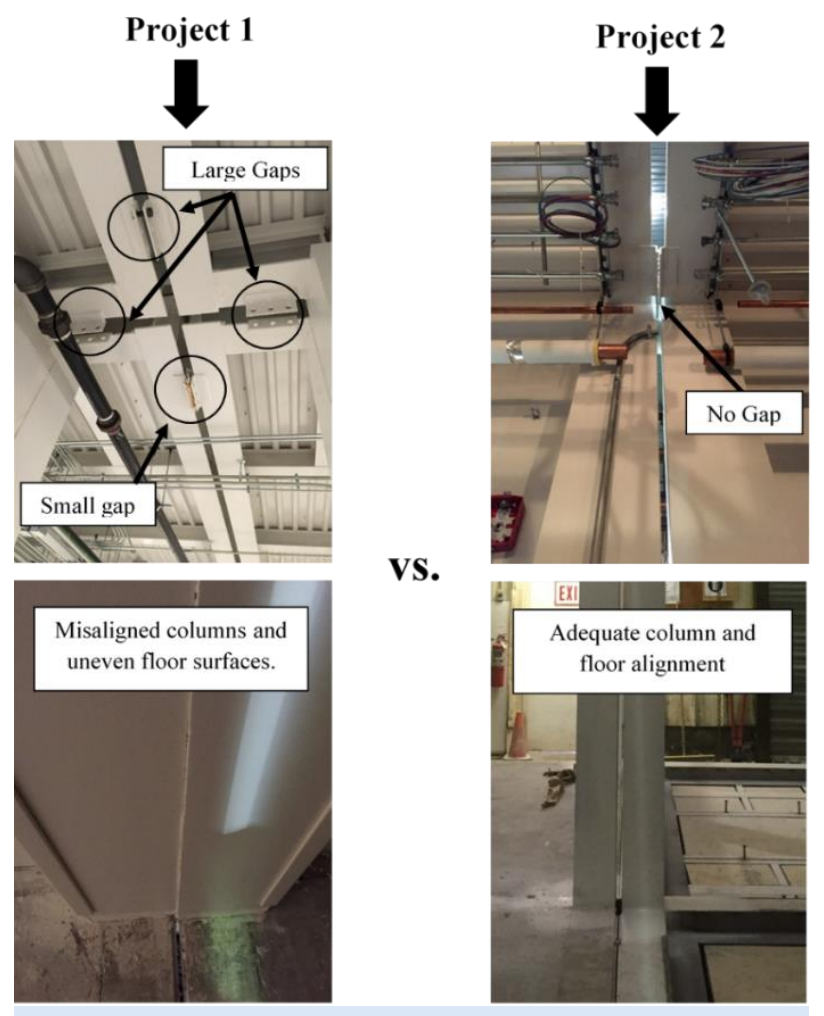

Figure 16. Comparison of the impacts on dimensional quality observed between Project 1 and Project 2

\section{Conclusions}

The study presented in this paper addresses a major challenge faced in the modular construction industry with respect to dimensional quality. Currently, there is a lack of comparative data across projects to establish benchmarks for dimensional quality. Dimensional variability of system components and non-conformance of adjacent modules leads to aggregation issues that impact modular construction projects in numerous ways. The potential impacts caused by poor dimensional quality were outlined in this paper as being rework, structural safety, constructability, aesthetics, and functionality. The currently available resources for tolerance specification merely function as worst-case limits and do not account for the bespoke needs of projects. Due to the production repetition found in modular construction systems, it is advantageous for contractors to quantify, benchmark and improve dimensional quality in a continuous manner. In this way, dimensional quality strategies can be tailored to specific fabrication, assembly, handling, and erection processes to improve the project outcome, and avoid rework.

Methods for quantifying dimensional variability were discussed and implemented through a case study on two identical modular construction projects. A 3D laser scanner and a total station were used to gather as-built dimensional data by creating point clouds and 3D coordinates of critical structural components. Measurements were then analyzed using scan-vs-BIM and statistical distribution analyses. A framework was used, stemming from research on continuous improvement in construction. While aggregation was a major challenge observed during the first project, it was effectively resolved in the second project. Although structural components such as tie-in plates, and framing members exhibited gaps and misalignment in the first project, the structural safety was not compromised, since provisions such as shims were used for achieving adequate connections between modules. These provisions did however cause extensive rework and resulted in an impact on the aesthetics of the structure. It should be noted that in high-rise modular building applications, structural safety is a more prevalent risk, which must be addressed through dimensional quality strategies. In the second project of the case study, the use of DfMA techniques, through reducing overall quantity of component deviation aggregation, aided in reducing dimensional variability of the flooring system. This resolved gaps between concrete panels and floor frames thus eliminating concern for structural safety impact and improving the overall aesthetics and functionality. Another management technique implemented was additional point supports to reduce midspan deflection. This resulted in fewer aggregation conflicts for crossmodule systems such as MEP, thereby improving the overall level of dimensional quality. Finally, the use of improved dimensional control during layout and fabrication of the structural assemblies resulted in fewer conflicts between modules on site, especially at key connection points.

The limitations faced in this case study primarily relate to the accuracy of the laser scanner used with respect to the reported deviations from analysis with BIM data. Since the laser scanner employed has a manufacturer-stated accuracy of $+/-3 \mathrm{~mm}$ at a distance of $10 \mathrm{~m}$, the reporting of any deviation values less than this threshold cannot be unequivocally made. Furthermore, the process of comparing as-built data with BIM data also introduces dimensional errors. Despite this limitation, many of the deviations reported in this case study did exceed this +/$3 \mathrm{~mm}$ limit and therefore are reliable figures. The other limitation of this study is the ability for the continuous improvement framework to reasonably account for variability in production processes. For instance, although the observed deviations for a given process might be $\mathrm{X}$ $\mathrm{mm}$ in one project, there is no guarantee that they will be $\mathrm{X} \mathrm{mm}$ in the next project (even if the two projects are identical). All production processes have inherent variability, which affects the observed dimensional quality. As such, rather than relying on the proposed framework as a tool for deterministically resolving 
dimensional quality issues, it should be used to probabilistically reduce risk.

While the case study in this paper outlines dimensional strategies for steel-framed modules, the process is generalizable to other types of modular projects as well. In steel-frame systems, a large source of dimensional variability stems from welding distortion which leads to fit-up problems on site. The proposed framework is shown to address this by first quantifying dimensional variability and subsequently developing stricter dimensional controls during production. In modular wood-framed systems, previous studies have shown that typical dimensional-related issues include structural movements during handling that causes drywall cracking and doors to not fit properly [62]. To mitigate these issues, the proposed framework could be used to quantify the amount of elastic movement occurring during transportation from which to develop and revise an adequate handling strategy (i.e., the authors have observed several modular contractors who employ the use of temporary bracing during transportation to minimize structural movements). In modular and prefabricated concrete systems, the dimensional quality of shear keys and flat ducts which connect between elements require very precise dimensional compliance [25]. Variability in the formwork used for casting concrete has a direct impact on overall dimensional quality. The proposed framework in this paper could be used to quantify the amount of variability caused by a given formwork method and used to develop production strategies (i.e., robotic production of formwork, which has greater precision than those produced manually) to ensure adequate dimensional quality is achieved. While these listed examples represent only a small subset of various modular construction systems, they demonstrate the versatility of the proposed framework for identifying, benchmarking and improving dimensional quality strategies in a continuous manner. In general, design and fabrication strategies should be documented and improved based on the dimensional quality impacts observed in each project. To do this, asbuilt dimensions need to be consistently measured throughout the lifecycle of a modular construction project to monitor performance.

\section{Acknowledgements}

The authors would like to acknowledge the financial support of the Natural Sciences and Engineering Research Council of Canada (NSERC), Mitacs Accelerate and Edge Architects. In addition, the authors would like to acknowledge the in-kind support of FARO Technologies Inc. Any opinions, findings, and recommendations made in this work are those of the authors and do not necessarily reflect the views of the stakeholders who have supported this research.

\section{References}

[1] Ferdous, W., Bai, Y., Ngo, T.D., Manalo, A., Mendis, P. (2019). "New advancements, challenges and opportunities of multi-storey modular buildings-A stateof-the-art review." Engineering Structures, 183, 883-893. https://doi.org/10.1016/j.engstruct.2019.01.061.

[2] Choi, J.O., O’Connor, J.T., Kwak, Y.H., Shrestha, B.K. (2019). "Modularization business case analysis model for industrial projects." Journal of Management in Engineering, 35(3), 04019004. https://doi.org/10.1061/(ASCE)ME.1943-5479.0000683.

[3] Lawson, M., Ogden, R., Goodier, C. (2014). "Design in modular construction." CRC Press, 978-0415554503.

[4] Yin, X., Liu, H., Chen, Y., Al-Hussein, M. (2019). "Building information modelling for off-site construction: Review and future directions." Automation in Construction, 101, 72-91. https://doi.org/10.1016/j.autcon.2019.01.010.

[5] Pan, W., Hon, C.K. (2018). "Modular integrated construction for high-rise buildings." Proceedings of the Institution of Civil Engineers-Municipal Engineer, 173(2), 64-68. https://doi.org/10.1680/jmuen.18.00028.

[6] Arashpour, M., Heidarpour, A., Akbar Nezhad, A., Hosseinifard, Z., Chileshe, N., Hosseini, R. (2019). "Performance-based control of variability and tolerance in off-site manufacture and assembly: optimization of penalty on poor production quality." Construction Management and Economics, 1-13. https://doi.org/10.1080/01446193.2019.1616789.

[7] Enshassi, M.S., Walbridge, S., West, J.S., Haas, C.T. (2019). "Integrated risk management framework for tolerance-based mitigation strategy decision support in modular construction projects." Journal of Management in Engineering, 35(4). https://doi.org/10.1061/(ASCE)ME.19435479.0000698.

[8] Talebi, S. (2019). "Improvement of dimensional tolerance management in construction." PhD thesis, University of Huddersfield. http://eprints.hud.ac.uk/id/eprint/35070.

[9] Shahtaheri, Y., Rausch, C., West, J., Haas, C., Nahangi, M. (2017). "Managing risk in modular construction using dimensional and geometric tolerance strategies." Automation in Construction, 83, 303-315. https://doi.org/10.1016/j.autcon.2017.03.011.

[10] Ballast, D.K. (2007). Handbook of Construction Tolerances, John Wiley \& Sons, Hoboken, NJ, USA.

[11] Milberg, C.T. (2006). "Application of tolerance management to civil systems." $\mathrm{PhD}$ thesis, University of California,

Berkeley. http://citeseerx.ist.psu.edu/viewdoc/download?doi=10.1. 1.308.5119\&rep=rep1\& type $=$ pdf. 
[12] Talebi, S., Koskela, L., Shelbourn, M., Tzortzopoulos, P. (2016). "Critical review of tolerance management in construction." Proceedings, 24th Annual Conference of the International Group for Lean Construction. Boston, MA, USA, Jul. 20-22, pp. 63-72.

[13] Acharjee, T. (2007). "Investigating accumulation of tolerances and its impact on reliability of job site installation. " MASc thesis, University of Cincinnati. http://rave.ohiolink.edu/etdc/view?acc_num=ucin 11728 $\underline{57125 .}$.

[14] Luo, L.-z., Mao, C., Shen, L.-y., Li, Z.-d. (2015). "Risk factors affecting practitioners' attitudes toward the implementation of an industrialized building system: A case study from China." Engineering, Construction and Architectural Management, 22(6), 622-643. https://doi.org/10.1108/ECAM-04-2014-0048.

[15] Wuni, I.Y., Shen, G.Q. (2019). "Barriers to the adoption of modular integrated construction: systematic review and meta-analysis, integrated conceptual framework, and strategies." Journal of Cleaner Production, 249, 119347. https://doi.org/10.1016/j.jclepro.2019.119347.

[16] Nahangi, M., Haas, C.T. (2014). "Automated 3D compliance checking in pipe spool fabrication." Advanced Engineering Informatics, 28(4), 360-369. https://doi.org/10.1016/j.aei.2014.04.001.

[17] Malisch, W.R., Suprenant, B.A. (2005). "ASCC Summary Report for the meeting of an Inter-industry Working Group on Reducing the Cost of Tolerance Compatibility Problems." 4-8. https://www.ascconline.org/PDF/ASCCtoleranceworksh opsummary.pdf (Accessed May 5, 2020).

[18] Rausch, C., Nahangi, M., Haas, C., Liang, W. (2019). "Monte Carlo simulation for tolerance analysis in prefabrication and offsite construction." Automation in Construction, 103, 300-314.

https://doi.org/10.1016/j.autcon.2019.03.026.

[19] Shahtaheri, Y. (2014). "A risk based approach to module tolerance specification." MASc thesis, University of Waterloo. http://hdl.handle.net/10012/8346.

[20] Liu, P., Chen, Y., Luo, X., Yu, Z., Long, H. (2019). "Dimensional tolerance control for prefabricated building components." ACI Structural Journal, 116(4), 101-114. https://doi.org/10.14359/51715629

[21] Gorgolewski, M.T., Grubb, P.J., Lawson, R.M. (2001). Modular construction using light steel framing. The Steel Construction Institute, SCI Publication P302, Ascot, Berkshire, UK. https://www.steelconstruction.info/images/2/2f/SCI_P30 2.pdf.

[22] Lawson, R.M., Richards, J. (2010). "Modular design for high-rise buildings." Proceedings of the Institution of
Civil Engineers-Structures and Buildings, 163(3), 151164. https://doi.org/10.1680/stbu.2010.163.3.151.

[23] Rausch, C., Nahangi, M., Perreault, M., Haas, C.T., West, J. (2016). "Optimum assembly planning for modular construction components." Journal of Computing in Civil Engineering, 04016039. https://doi.org/10.1061/(ASCE)CP.1943-5487.0000605.

[24] Kim, M., Wang, Q., Park, J., Cheng, J.C., Sohn, H., Chang, C. (2016). "Automated dimensional quality assurance of full-scale precast concrete elements using laser scanning and BIM." 72, 102-114. https://doi.org/10.1016/j.autcon.2016.08.035.

[25] Wang, Q., Kim, M., Cheng, J.C., Sohn, H. (2016). "Automated quality assessment of precast concrete elements with geometry irregularities using terrestrial laser scanning." Automation in Construction, 68, 170182. https://doi.org/10.1016/j.autcon.2016.03.014.

[26] Kalasapudi, V.S., Turkan, Y., Tang, P. (2014). "Toward automated spatial change analysis of MEP components using 3D point clouds and as-designed BIM models." Proceedings, International Conference on 3D Imaging, Modeling, Processing, Visualization and Transmission (3DIMPVT), Tokyo, Japan, Dec. 8-11, pp. 145-152. https://doi.org/10.1109/3DV.2014.105.

[27] Anil, E.B., Tang, P., Akinci, B., Huber, D. (2013). "Deviation analysis method for the assessment of the quality of the as-is building information models generated from point cloud data." Automation in Construction, 35, 507-516. https://doi.org/10.1016/j.autcon.2013.06.003.

[28] Golparvar-Fard, M., Bohn, J., Teizer, J., Savarese, S., Peña-Mora, F. (2011). "Evaluation of image-based modeling and laser scanning accuracy for emerging automated performance monitoring techniques." Automation in Construction, 20(8), 1143-1155. https://doi.org/10.1016/j.autcon.2011.04.016.

[29] Tang, P., Anil, E., Akinci, B., Huber, D. (2011). "Efficient and effective quality assessment of as-is building information models and 3D laser-scanned data." Computing in Civil Engineering, 19-22. https://doi.org/10.1061/41182(416)60.

[30] Bosché, F., Ahmed, M., Turkan, Y., Haas, C.T., Haas, R. (2015). "The value of integrating Scan-to-BIM and Scan-vs-BIM techniques for construction monitoring using laser scanning and BIM: The case of cylindrical MEP components." Automation in Construction, 49, 201213. https://doi.org/10.1016/j.autcon.2014.05.014.

[31] Kalasapudi, V.S., Tang, P., Turkan, Y. (2017). "Computationally efficient change analysis of piece-wise cylindrical building elements for proactive project control." Automation in Construction, 81, 300-312. https://doi.org/10.1016/j.autcon.2017.04.001. 
[32] Czerniawski, T., Nahangi, M., Haas, C., Walbridge, S. (2016). "Pipe spool recognition in cluttered point clouds using a curvature-based shape descriptor." Automation in Construction, 71, 346-358. https://doi.org/10.1016/j.autcon.2016.08.011.

[33] Bosché, F. (2010). "Automated recognition of 3D CAD model objects in laser scans and calculation of asbuilt dimensions for dimensional compliance control in construction." Advanced engineering informatics, 24(1), 107-118. https://doi.org/10.1016/j.aei.2009.08.006.

[34] Xiao, Y., Feng, C., Taguchi, Y., Kamat, V.R. (2017). "User-guided dimensional analysis of indoor building environments from single frames of RGB-D sensors." Journal of Computing in Civil Engineering, 31(4), 04017006. https://doi.org/10.1061/(ASCE)CP.1943$\underline{5487.0000648 .}$.

[35] Kim, M., Wang, Q., Li, H. (2019). "Non-contact sensing based geometric quality assessment of buildings and civil structures: A review." Automation in Construction, 100, 163-179. https://doi.org/10.1016/j.autcon.2019.01.002.

[36] Jensen, P., Olofsson, T., Johnsson, H. (2012). "Configuration through the parameterization of building components." Automation in Construction, 23, 1-8. https://doi.org/10.1016/j.autcon.2011.11.016.

[37] Farr, E.R., Piroozfar, P.A., Robinson, D. (2014). "BIM as a generic configurator for facilitation of customisation in the AEC industry." Automation in Construction, 45 , 119-125.

https://doi.org/10.1016/j.autcon.2014.05.012.

[38] Cao, J., Hall, D. (2019). "An overview of configurations for industralized construction: typologies, customer requirements, and technical approaches." Proceedings, 2019 European Conference on Computing in Construction, Zurich, Switzerland, Jul. 10-12, pp. 295303. http://www.doi.org/10.35490/EC3.2019.145.

[39] Jansson, G., Johnsson, H., Engström, D. (2014). "Platform use in systems building." Construction Management and Economics, 32(1-2), 70-82. https://doi.org/10.1080/01446193.2013.793376.

[40] Martinez, P., Ahmad, R., Al-Hussein, M. (2019). "Automatic selection tool of quality control specifications for off-site construction manufacturing products: A BIMbased ontology model approach." Proceedings, Modular and Offsite Construction (MOC) Summit, Banff, Alberta, Canada, May 21-24, pp. 141-148. https://doi.org/10.29173/mocs87.

[41] An, S., Martinez, P., Ahmad, R., Al-Hussein, M. (2019). "Ontology-based knowledge modeling for frame assemblies manufacturing", Proceedings, 36th International Symposium on Automation and Robotics in Construction, Banff, Alberta, Canada, May 21-24, pp. 709-715. https://doi.org/10.22260/ISARC2019/0095.
[42] Gbadamosi, A., Mahamadu, A., Oyedele, L.O., Akinade, O.O., Manu, P., Mahdjoubi, L., Aigbavboa, C. (2019). "Offsite construction: Developing a BIM-based optimizer for assembly." Journal of Cleaner Production, 215 ,

1180-1190.

https://doi.org/10.1016/j.jclepro.2019.01.113.

[43] Yuan, Z., Sun, C., Wang, Y. (2018). "Design for Manufacture and Assembly-oriented parametric design of prefabricated buildings." Automation in Construction, 88, 13-22. https://doi.org/10.1016/j.autcon.2017.12.021.

[44] Arashpour, M., Miletic, M., Williams, N., Fang, Y. (2018). "Design for manufacture and assembly in off-site construction: Advanced production of modular façade systems." Proceedings, $35^{\text {th }}$ International Symposium on Automation and Robotics in Construction, Berlin, Gernmany, Jul. 20-25, pp. 224-229. https://doi.org/10.22260/ISARC2018/0032.

[45] Chen, K., Lu, W. (2018). "Design for manufacture and assembly oriented design approach to a curtain wall system: A case study of a commercial building in Wuhan, China." $\quad$ Sustainability, 10(7), 2211. https://doi.org/10.3390/su10072211.

[46] BCSA. (2017)."National Structural Steelwork Specification (NSSS) for Building Construction." 6th Edition, ed., The British Constructional Steelwork Association, UK.

[47] Boyd, N., Khalfan, M.M., Maqsood, T. (2012). "Offsite construction of apartment buildings." Journal of Architectural Engineering, 19(1), 51-57. https://doi.org/10.1061/(ASCE)AE.1943-5568.0000091.

[48] Sege, V., Balta, P. (2019). "Benefits \& barriers of implementing reconfigurable jigs: A study in offsite manufacturing of unique house elements in Sweden." MASc. thesis, Jönköping University. urn:nbn:se:hj:diva$\underline{45194 .}$.

[49] Martinez, P., Ahmad, R., Al-Hussein, M. (2019). "A vision-based system for pre-inspection of steel frame manufacturing." Automation in Construction, 97, 151163. https://doi.org/10.1016/j.autcon.2018.10.021.

[50] Hamledari, H., McCabe, B., Davari, S. (2017). "Automated computer vision-based detection of components of under-construction indoor partitions." Automation in Construction, 74, 78-94. https://doi.org/10.1016/j.autcon.2016.11.009.

[51] Building and Construction Authority, Design for Manufacturing and Assembly (DfMA) Prefabricated Mechanical, Electrical, Plumbing (MEP) Systems, (2018).

https://www.bca.gov.sg/cpc/others/MEP_Guidebook_fin al.pdf (Accessed April 30, 2019).

[52] Zhang, D., Haas, C.T., Goodrum, P.M., Caldas, C.H., Granger, R. (2012). "Construction small-projects rework 
reduction for capital facilities." Journal of Construction Engineering and Management, 138(12), 1377-1385. https://doi.org/10.1061/(ASCE)CO.1943-7862.0000552.

[53] Sun, M., Meng, X. (2009). "Taxonomy for change causes and effects in construction projects." International Journal of Project Management, 27(6), 560-572. https://doi.org/10.1016/j.ijproman.2008.10.005.

[54] Love, P.E., Smith, J. (2003). "Benchmarking, benchaction, and benchlearning: rework mitigation in projects." Journal of Management in Engineering, 19(4), 147-159. $\quad$ https://doi.org/10.1061/(ASCE)0742597X(2003)19:4(147).

[55] Mohamed, S. (1996). "Benchmarking and improving construction productivity." Benchmarking for Quality Management \& Technology, 3(3), 50-58. https://doi.org/10.1108/14635779610149151.

[56] Nasir, H., Haas, C.T., Rankin, J.H., Fayek, A.R., Forgues, D., Ruwanpura, J. (2012). "Development and implementation of a benchmarking and metrics program for construction performance and productivity improvement." Canadian Journal of Civil Engineering, 39(9), 957-967. https://doi.org/10.1139/12012-030.

[57] ACI, (2002)."ACI Committee 117, Commentary on Standard Specifications for Tolerances for Concrete Construction and Materials (ACI 117-06)." American Concrete Institute, Farmington Hills, Michigan.

[58] AISC, Specification for Structural Steel Buildings (ANSI/AISC 360-10) (2010). https://www.aisc.org/globalassets/aisc/publications/stand ards/a360-16-spec-and-commentary.pdf (Accessed Feb. 2, 2019).

[59] American Concrete Institute (2004)."Building Code Requirements for Structural Concrete (ACI 318-05) and Commentary (ACI 318R-05)", American Concrete Institute.

[60] FARO, FARO BuildIT Construction Software Techsheet, FARO Technologies, Inc. (2019). https://insights.faro.com/buildit-construction/techsheetfaro-buildit-construction (Accessed Nov. 26, 2019).

[61] AISC (2010)."Code of Standard Practice for Steel Buildings and Bridges (AISC 303-10)." American Institute of Steel Construction, Chicago, Illinois.

[62] Johnsson, H., Meiling, J.H. (2009). "Defects in offsite construction: timber module prefabrication." Construction Management and Economics, 27(7), 667681. 